\title{
Aportes arqueológicos al estudio de la cadena de producción de imágenes: El caso del petroglifo de "La Libertad"
}

Juan López Escorza'

\begin{abstract}
RESUMEN
El ObJeTIVO PRINCIPAL DE ESTE ARTículo ES CONTRIBUIR AL ANÁLISIS SOBRE UN TIPO DE TECNOLOGía Lítica Y SUS POSIBLES VINCULACIONES CON EL ARTE RUPESTRE DE UN SECTOR DEL SUBTRÓPICO ECUATORIANO. CON EL AFÁN DE ENTENDER MEJOR CÓMO EL HOMBRE TEMPRANO DE ESTA REGIÓN PUDO HABER EMPLEADO TÉCNICAS Y HERRAMIENTAS PARA LA ELABORACIÓN DE GRABADOS, EL PRESENTE TRABAJO SE ENMARCA ALREDEDOR DE LOS HALLAZGOS DE DEPÓSITOS DE CINCELES ALREDEDOR DEL PETROGLIFO DEL SITIO DENOMINAdo LA LibERTAD, UBICADO EN LA PARRoQUia SAN LUIS de Pambil, provincia de Bolívar.
\end{abstract}

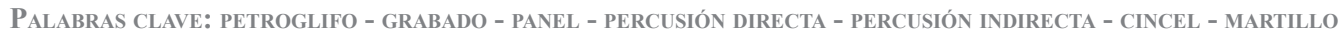
DE PIEDRA

\section{Abstract}

The MAIN AIM OF THIS ARTICle IS TO CONTRIBUTE TO THE ANALYSIS OF A TYPE OF LITHIC TECHNOLOGY AND ITS POSSIBLE LINKS WITH CAVE PAINTING FROM A SECTOR OF THE ECUADORIAN SUBTROPICS. WiTH THE GOAL OF BETTER UNDERSTANDING HOW ANCIENT MAN IN THIS REGION MIGHT HAVE EMPLOYED TECHNIQUES AND TOOLS FOR THE PRODUCTION OF ENGRAVINGS, THIS PAPER IS FRAMED ON THE DISCOVERY OF ARCHEOLOGICAL DEPOSITS OF CHISELS around the petroglyph site called la Libertad, located in the parish of San Luis de Pambil, Bolívar PROVINCE.

Key WORds: Petroglyph/ROCK ENGRAVIng - (ROCK) CARVING - PANELING/BoARd - DIRECT PERCUSSION - INDIRECT PERCUSSION - CHISEL - STONE HAMMER. 


\section{Introducción}

T o poco que conocemos de la geología de la provincia Bolívar, nos ha impedido tener una visión más amplia de su composición estratigráfica y sobre todo de su litología. Sin embargo, la escasa información nos da una pauta para entender, a grosso modo, esta estructura. Primeramente, es necesario señalar que el sitio de estudio se encuentra en las tierras bajas de la provincia concretamente en la zona subtropical, que se desprende de las estribaciones de la cordillera occidental y forma parte del conjunto sedimentario del litoral. A lo largo de esta transición hacia las tierras bajas se observan grandes afloramientos de roca basáltica y más hacia los 800 m.s.n.m. inclusive tenemos importantes afloramientos de cuarcita. Wolf (1897) menciona a breves rasgos la presencia de varios metales en la zona como oro, y piedras como la pirita y la cuarcita; mientras que Acosta Solís (1979), menciona que las formaciones geológicas de esta zona favorecen el aparecimiento de metales como el hierro y elementos como el carbón.

En relación a la filiación cultural de la zona, hemos otorgado algunos criterios en nuestro estudio sobre los petroglifos de San Luis de Pambil (López Escorza, 2008) basados concretamente en los siguientes aspectos: la presencia de montículos, la presencia de cerámica y casos concretos comparativos a nivel iconográfico. Del material que se observó a partir del año 2008 (Ibid.) concluimos hipotéticamente que la cultura que ocupó este sector de la provincia podría ser Milagro-Quevedo, frente a lo cual no dudamos sobre este argumento. En nuestro trabajo, identificamos también un motivo zoomorfo grabado en el petroglifo de Campo Bello, que tiene la forma del rostro del búho, común en la cerámica y en ciertos objetos de metalurgia Milagro-Quevedo (Ibid.). En síntesis, esto nos ha permitido asociar, hipotéticamente, la filiación cultural de estos petroglifos al periodo de Integración. La cercanía a la provincia de Los Ríos, en donde investigó Estrada (1979) y posteriormente Porras (1983) fortalece aún más esta filiación cultural luego de que identificaron varios sitios Milagro-Quevedo, concretamente los sitios de Chilintomo, Palenque, Quevedo.

Igualmente, petroglifos registrados recientemente muy cerca de San Luis de Pambil fortalecen nuestra propuesta ${ }^{2}$ de filiación cultural con esta cultura. Otro posible indicador que hemos sugerido en nuestro estudio, ya con mucha antelación, es la presencia de una ruta precolombina que converge con zonas por los cuales entendemos se expandió parte de esta cultura.

Hemos propuesto anteriormente que Milagro-Quevedo, debió mantener un comercio intenso con los Puruhá que se asentaron en las tierras altas de Bolívar. Muy probablemente el intercambio de la sal de Chachipamba (Salinas de Tomavela) era intercambiada por otros productos con la costa. Hemos planteado igualmente en nuestro estudio de 2008, la hipótesis de una posible frontera cultural marcada por los petroglifos de esta zona, sin dejar de lado de que ésta podría ser apenas una de las varias funciones que estos objetos cumplieron en este territorio de transición.

La falta de evidencias empíricas y las limitaciones metodológicas han opacado nuestra capacidad de responder a preguntas muy básicas en el estudio de la tecnología vinculada al arte rupestre: ¿cómo se hicieron los grabados en piedra? y ¿qué herramientas se utilizaron? Pensamos ahora, que al abordar el arte rupestre es necesario también enfocarnos en el proceso tecnológico implicado en su producción, en las cantidades de mano de obra dedicada a la elaboración, refacción y reutilización de herramientas para el trazado de grabados.

En general, los procesos de manufactura de petroglifos sigue siendo uno de los menos conocidos en arqueología, inclusive en regiones que gozan de amplios conjuntos de petroglifos como la amazonía y las estribaciones de la cordillera occidental ecuatorianas. Fiore (1999)

2 Bravo y Vargas (2012), inventario de petroglifos apoyado por el INPC, y recientemente analizados desde el enfoque de la arqueología del paisaje por Toscano (2014). 


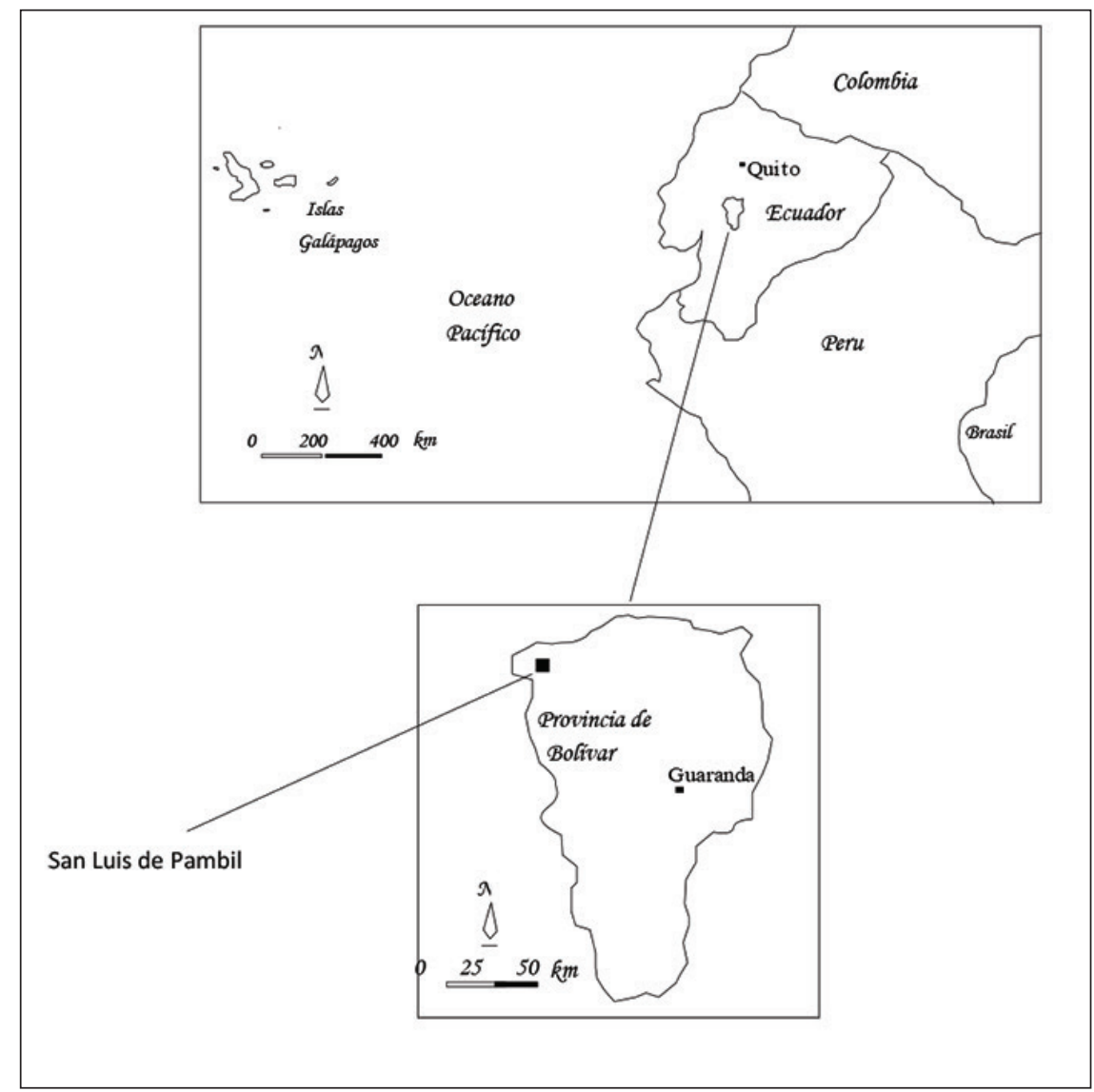

Figura 1: Ubicación de San Luis de Pambil, provincia de Bolìvar. (López E. 2009).

menciona que el problema de la "falta de evidencia empírica" no siempre puede ser un sinónimo de ausencia o escasez, sino una falta de atención del arqueólogo en varios aspectos: “1) podría estar relacionada con un problema de muestreo; 2) podría estar relacionada con un problema de procesos de formación de registro arqueológico, tanto naturales como culturales; y 3 ) podría estar relacionada con un problema de reconocimiento arqueológico de los artefactos" (Ibid.: 281).

Podemos asumir que los individuos que manufacturaron los petroglifos en épocas prehispánicas debieron invertir considerables cantidades de tiempo y energía. ¿Cómo podemos explicar este gasto? (Ibid.). Para una mayor acercamiento metodológico a la tecnología implicada en la producción de imágenes, Fiore (Ibid.) sugiere que esta puede ser abordada a partir de la síntesis metodológica de la cadena operatoria ${ }^{3}$. A breves rasgos, esto quiere decir que a la elaboración de los grabados en piedra le antecede un amplio proceso de producción, desde la selección de la materia prima, elaboración de herramientas de precisión; hasta su

3 El concepto de cadena operativa considera las siguientes etapas: obtención de recursos, la manufactura de un determinado producto, el/los uso/s del mismo, la posibilidad de su mantenimiento mediante procedimientos específicos o su reciclaje transformándolo en otro producto. En el caso de los artefactos (no así de las imágenes rupestres, emplazadas en un soporte fijo), pueden ocurrir el almacenamiento, la pérdida y el abandono, lo cual posibilita la incorporación de los mismos al contexto arqueológico. (Fiore, 1999: 278). 
uso, que implica la refacción y mantenimiento durante el proceso de grabado de imágenes en las rocas. Sin embargo, ha diferencia de otras cadenas operatorias, debemos entender que la cadena de producción de imágenes es muy especializada, de tal manera que hay una alta probabilidad de encontrar técnicas y herramientas no tan comunes en otros contextos de producción de tecnología lítica.

Para distinguir los procesos tecnológicos vinculados a la manufactura de petroglifos utilizaremos a lo largo de este artículo el término de cadena de producción de imágenes empleado por Fiore (Ibid.) quien igualmente incluye en el proceso de esta cadena las siguientes etapas: a) obtención de recursos, b) manufactura, c) uso, d) mantenimiento, e) reciclaje, f) descarte, g) pérdida, h) abandono, i) almacenamiento (Ibid.).

Algunos criterios se van sumando a la precariedad de datos sobre esta cadena para volverla una verdadera fuente de información, entre ellos la energía invertida, los estudios de la arqueología experimental aplicada al arte rupestre, entre otros, permiten abrir nuestras expectativas entorno a lo que conocemos actualmente. A lo largo de las próximas líneas expondremos algunos de estos criterios a fin de que sean un insumo para los hallazgos con los que contamos provenientes de un yacimiento de las estribaciones de la cordillera occidental ecuatoriana.

\section{¿Martillo y cincel, o herramienta única?}

A breves rasgos, la problemática sobre la cadena de producción de imágenes de petroglifos se puede resumir en dos tendencias teóricas: una de ellas sostiene que los individuos que realizaron los grabados utilizaron una única herramienta llamada "martillo de piedra", al cual se asocia la técnica de percusión directa; $y$, la otra tendencia plantea que se usaron al menos dos herramientas para hacer grabados: el martillo y el cincel; comúnmente denominada técnica de percusión indirecta. Esta última hace alusión al uso de una herramienta intermediaria como un cincel entre el material u objeto martillado y el martillo, siendo la superficie de la roca como el objeto de esta percusión indirecta. Algunas variables han determinado el éxito de esta técnica, y por ello podemos considerarla como la más común dentro de estas dos tendencias. Según Gilreath (1997) éstas se resumen en tres variables generales, a las cuales hemos considerado ampliarles con una breve definición:

- La dureza de la roca, el cual se puede determinar mediante varios ensayos con artefactos experimentales no arqueológicos sobre superficies de roca.

- El material y diseño del cincel, que se determinaría por la forma del cincel, sus lados o extremos utilizables, como también su espesor en relación a los surcos de los grabados.

- La habilidad del grabador, que se determinaría por la precisión o complejidad de los grabados.

Desde nuestra perspectiva, dentro de estas variables hay aspectos que generan una especie de feedback en el análisis, es decir, no solo las herramientas en si mismas nos ayudan ha entender el proceso de manufactura, también en sentido inverso, donde las acanaladuras o surcos de los grabados son indicadores -al mismo tiempo- del tipo de herramientas y de su eficacia. Algunos de estos aspectos suelen ser comunes en el desarrollo de experimentos replicativos de técnicas de grabados en piedra que por lo general responden a los problemas o limitaciones que mencionamos al inicio y que se enmarcan en lo que algunos llaman arqueología experimental ${ }^{4}$, la cual pensamos que encuentra gran asidero en el arte rupestre.

4 Flaherty (2012: 48) señala: "La arqueología experimental es el estudio del comportamiento en el pasado, tratando de replicar ciertos aspectos de modos de vida prehistóricos o históricos".. 
Algunos de estos estudios experimentales realizados en el cono sur son los de Álvarez y Fiore (1995) en el sudoeste de la provincia de Río Negro, Patagonias; y, los de Blanco y Lynch (2011) en Santa Cruz, Argentina. En estos dos estudios experimentales se pusieron a prueba tres técnicas: incisión, raspado y horadación ${ }^{6}$. En estos sitios los artefactos empleados fueron "artefactos no formalizados" elaborados en sílice y aplicando la técnica de percusión directa. Como resultado de esta experimentación se estableció que los motivos arqueológicos pudieron grabarse por "artefactos no formalizados", mismos que se consideraron como de fácil prensión y sin necesidad de enmangue. A partir de ello Álvarez y Fiore (1995, en: Blanco y Lynch, 2011) concluyen:

"Es posible la producción de motivos grabados a partir de un solo instrumento, el cual no necesariamente tiene que ser sofisticado o diseñado especialmente para tal efecto". (Ibid.: 18).

Los resultados obtenidos de los experimentos de Álvarez y Fiore sugieren que algunos estilos de grabados pudieron hacerse con una sola herramienta, es decir por percusión directa y no necesariamente con dos herramientas. Otras experimentaciones de manufactura de petroglifos son las realizadas por Whittaker y Koeman (2000) en el sudoeste de Arizona en donde pusieron a prueba la efectividad de la percusión directa y la percusión indirecta, enfatizando en criterios muy relevantes, por ejemplo la eficiencia y la durabilidad. Estos aspectos fueron inferidos por los autores experimentando varias técnicas de grabado, que son las siguientes:

- $\quad$ picoteo, realizado con pedernal afilado, lascas de sílex y cuarcita

- golpeteo, con pedernal afilado

- $\quad$ cincelado, con punta de cornamenta

- $\quad$ incisión, con lascas de sílex (Ibid.: 159).

Aunque cada una de las técnicas experimentadas produjeron diferentes resultados, concluyeron que la técnica del picoteo fue la más eficiente de todas, tomó menos tiempo realizar un grabado que con las otras técnicas, además de que demostró un mejor control sobre la herramienta; la superficie utilizada para la experimentación fue la roca arenisca en este caso. En oposición a Gilreath (1997) que defiende la tesis de la percusión indirecta, la experimentación de Whittaker y Koeman (2000) arroja algo completamente diferente, señalando que la percusión indirecta no siempre es la más eficiente.

Los estudios de arqueología experimental parecen mostrar distintos resultados que están determinados por varios factores como la dureza de la roca, el material de las herramientas, etc. Sin embargo, dentro de estos estudios experimentales se han planteado otras variables directamente relacionadas con los individuos que realizaron los grabados, por ejemplo, el gasto de energía para la producción de imágenes. Flaherty (2012) analiza este aspecto a partir de los siguientes criterios: en primer lugar, el tiempo aproximado que se requiere para que un individuo fabrique un petroglifo tenía que ser establecida. En segundo lugar, el tiempo que se necesita para crear un petroglifo tuvo que ser convertido matemáticamente en unidades de energía (Ibid.: 57). Aparte de la aplicación de las fórmulas matemáticas implícitas para este análisis se incluye el análisis calorimétrico común en los estudios fisiológicos pero que han tenido extraordinaria aplicación en las investigaciones antropológicas.

5 Los sitios de estudio: cuevas Sarita I, Sarita II, Sarita III, Sarita IV, paredón Alonso, cuevas Alonso I, Alonso II, Abrigo de Pilcaniyeu y cueva Ceferino II (Fiore, 1999: 280).

6 Blanco y Lynch (2011) las definen así: Incisión: implica el corte o hendidura del soporte mediante el movimiento unidireccional del artefacto, cuyo filo se desplaza en forma paralela a la dirección de la utilización. Raspado: se trata de la abrasión del soporte mediante el movimiento bidireccional del artefacto, cuyo filo se desplaza en forma perpendicular a la dirección de utilización. 2 Horadación: implica la inserción gradual de un artefacto en el soporte mediante movimientos de rotación en sentido horario y antihorario (Ibid.: 12). 


\section{El petroglifo del sitio La Libertad, un caso de estudio de tecnología rupestre}

El sitio La Libertad está ubicado en la parroquia de San Luis de Pambil, provincia de Bolívar, en donde la cordillera de Chimbo determina las características geológicas de esta provincia formando dos zonas importantes: la andina oriental y la occidental subtropical (Wolf, 1897). La primera con dos pisos ecológicos como el páramo andino de clima frío y suelo desértico que asciende a más de 3.000 m.s.n.m.; el suelo andino montañoso-irregular con bosque montano y de clima templado bajo los 2.850 m.s.n.m.; y la segunda región del lado occidental de la cordillera de Chimbo corresponde al suelo subtropical con alturas que fluctúan entre los 400 y 300 m.s.n.m. Aquí las temperaturas alcanzan entre $\operatorname{los} 18^{\circ}$ a $24^{\circ}$ con precipitaciones anuales de 2000 a 4000 m.m. (Wolf 1897). En este sector el piso climático subtropical es también llamado Piso Pre-Montano-Subtropical y se despliega en el límite con la Provincia de Los Ríos. Esta área se conforma por varios bloques con rellenos o depósitos molásticos, aluviales, proluviales y conos de inyección de origen cuaternario (Wolf, 1987). Por otra parte, en el sector se despliegan importantes cerros que modelan su geografía (cerro Huagraurcu, cerro Pambila), a su vez el sector de San Luis de Pambil es irrigado por importantes fuentes hídricas que se originan en las vertientes del río Chimbo.

De los materiales arqueológicos no reportados de la misma zona (compoteras, vasijas de tres patas, hachas de cobre, llipteros, figurinas), se deduce la presencia de varias ocupaciones prehispánicas todavía no determinadas culturalmente ni cronológicamente. Sin embargo, luego de haber constatado algunos materiales cerámicos hallados por moradores del sector se pueden asociar al periodo de Integración, toda vez que muestran relaciones estilísticas con la cerámica de la costa ecuatoriana especialmente con Milagro-Quevedo, además con la particularidad de que el sector está dentro del sistema fluvial del Litoral, lo cual motiva este argumento de relación cultural con Milagro-Quevedo y que la planteamos en 2008. El petroglifo del sitio La Libertad fue registrado por López Escorza en el 2008, otorgando especial atención al hallazgo de las herramientas líticas como parte de un caso único en relación a los otros petroglifos del sector. Durante la prospección de los petroglifos del territorio de la parroquia se encontró al sitio de la Libertad compuesto por un petroglifo a una elevación de 220 m.s.n.m. y con las siguientes dimensiones: 2, $94 \mathrm{mts}$. de largo; 1,54 mts.. ancho; y $35 \mathrm{~cm}$. de alto (López Escorza, 2009: 27). Iniciamos limpiando los bordes de este petroglifo porque algunos de sus grabados estaban parcialmente cubiertos por vegetación.

Se procedió a remover parte de la capa vegetal superficial que rodea el perfil del petroglifo a una profundidad promedio de 20 a $30 \mathrm{~cm}$. A partir de esta profundidad los artefactos líticos comenzaron a aparecer con una fuerte concentración en uno de los costados de la piedra. Todavía no podemos determinar el por qué de esta acumulación de herramientas en un mismo lugar. Pensamos que esta acumulación no podría responder a una acción voluntaria basada solamente en la idea de descarte porque gran parte de las herramientas que logramos identificar están completas y aparentemente reutilizadas, rodeadas de escasos fragmentos. Por cuestiones de tiempo, no logramos realizar una excavación en el depósito, pero la prospección de superficie nos dio una idea muy convincente de que el depósito es mucho más profundo y de que su contenido es mucho más grande de lo que pudimos rescatar.

La mayor cantidad de artefactos líticos encontrados junto al petroglifo corresponden a herramientas tipo cincel, mientras que un porcentaje muy mínimo corresponde a pequeños percutores y retocadores. Durante el análisis de laboratorio, logramos determinar que la mayoría de los cinceles presentan desgastes graduales y huellas de uso, con mayor predominancia en uno de los extremos de cada herramienta; pudimos identificar herramientas de andesita y basalto. La zona de mayor desgaste de la herramienta sugiere un deterioro gradual posiblemente producido por la actividad de fricción constante, o tal vez por picoteo sobre la superficie de la roca. Identificamos al menos dos tipos de herramientas tipo cincel cuyas dimensiones oscilan entre los $12 \mathrm{~cm}$. y los $8 \mathrm{~cm}$; en promedio se trata de herramientas pequeñas pero muy aprensibles y manejables para la mano. 


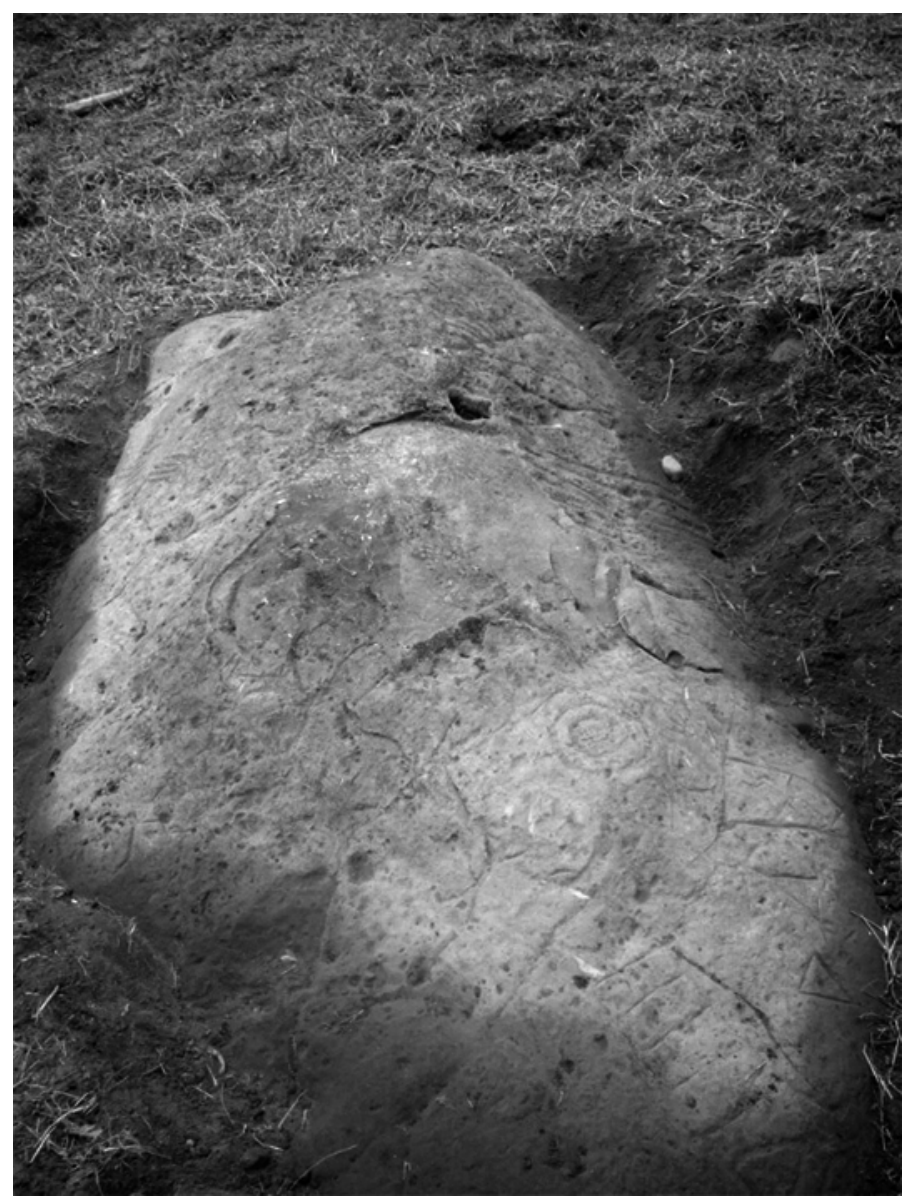

Figura 2: Petroglifo del sitio La Libertad. Foto: Juan López Escorza, 2009.

El primer tipo de herramienta semeja a una especie de cincel bifuncional, es decir, con dos puntas utilizables, una punta en cada extremo (figuras 2 y 3) sugiriendo que una vez desgastado el un extremo se utilizaba el otro. Sin embargo, su desgaste como su doble punta no sugiere que estos fueran golpeados por otra herramienta, por lo que podríamos compararlos con la forma de las herramientas de hueso propuestos por Fiore (1999) en su estudio del sitio de Río Negro, asociadas a percusión directa. Esto podría explicar algo de la función de estas herramientas por la utilidad y forma de la punta para la realización del grabado. En este sentido no estamos muy seguros si el término "cincel" para el primer tipo de herramienta encontrada sea el adecuado.

El segundo tipo de cinceles se caracterizan por tener una punta en un extremo y en el otro extremo una superficie lisa, que con seguridad son planos de golpe (figuras 4 y 5). Este segundo tipo sugiere que se tratan de un tipo diferente de herramienta, también llamada herramienta intermediaria, porque actúa entre la superficie de la roca y el martillo de piedra. Al respecto, en el mismo depósito se encontraron artefactos redondos con huellas de golpes en su superficie. Estos podrían ser martillos de piedra, sin embargo, no los tomamos en cuenta por su gran deterioro y escasa cantidad. Independientemente de estos posibles martillos de piedra, las herramientas cincel del segundo tipo (con plano de golpe en un extremo) podrían sugerir que se estaba utilizando también otra técnica, la percusión indirecta. 
La procedencia de la materia prima para la manufactura de estas herramientas se pudo determinar gracias a la comparación entre el material del cual estaban hechos los cinceles con varios monolitos cercanos ubicados entre los 8 y 12 metros de distancia del sitio, así como en la comparación con los escasos núcleos encontrados alrededor del depósito. Las herramientas tipo cinceles, no estaban por mera casualidad depositadas y acumuladas alrededor del petroglifo, por lo que debieron haber tenido relación funcional con este. Wiessner (1983) menciona que los instrumentos líticos acarrean un importante índice de información social, de esta manera el contexto in situ debidamente registrado permite determinar las actividades relacionadas con la cadena de producción de imágenes. Las herramientas sugieren una larga y consolidada tradición y especialización de los individuos la producción de esta cadena.

Por ahora, no hemos podido establecer los distintos procesos de la cadena mencionada anteriormente, toda vez que la muestra obtenida no es suficiente, pues no constatamos las preformas que anteceden al artefacto terminado. Un dato de relevancia ha sido el que se obtuvo a través del análisis de los tipos de acanaladuras, surcos e incisiones de los grabados, tres tipos de rasgos que planteamos para nuestro estudio.

En base a la medición de la profundidad y del ancho de estos rasgos de los grabados se logró determinar que en la mayoría de los casos estas coinciden con el diámetro de los extremos utilizados de las herramientas. Por ejemplo, en distintos grabados se encuentran distintos diámetros de incisiones y acanaladuras, en algunos casos llegan al medio centímetro de ancho, en otros casos desde $1 \mathrm{~cm}$. hasta $2 \mathrm{~cm}$. Se presentan también medidas de hasta $3 \mathrm{~cm}$. de ancho7. En promedio existe una importante correspondencia en el diámetro de algunas incisiones que oscilan entre los $0.5 \mathrm{~cm}$. y $1 \mathrm{~cm}$. de ancho con el diámetro del extremo desgastado de algunas herramientas. En este caso, aquellas que miden menos de $1 \mathrm{~cm}$ serían incisiones y no surcos.

El inconveniente surgido durante este análisis fue que algunos surcos cuyo ancho oscila entre los $3 \mathrm{~cm}$., no permitieron establecer correspondencia directa con alguno de los cinceles encontrados, excepto que se puedan obtener surcos más anchos por percusión indirecta. Podemos plantear, por ahora, tres distintos tipos de rasgos que indican el empleo de más de un tipo de herramienta sobre la superficie de este petroglifo:

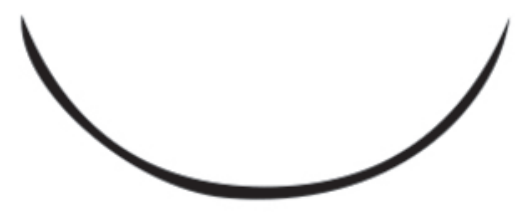

A. Acanaladura o surco
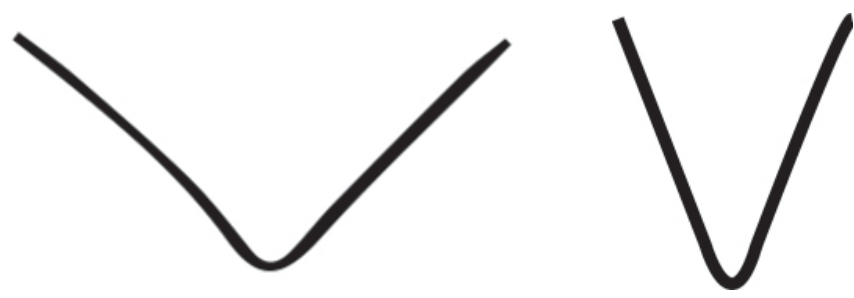

INCISIONES B Y C

7 Las características estilísticas y las técnicas del conjunto de grabados del petroglifo de La Libertad están descritas por el autor en su investigación sobre los petroglifos de San Luis de Pambil (PUCE). 
El tipo de roca del sitio puede facilitar o endurecer la realización de estos rasgos, en este caso, durante la primera visita al sitio se pudo observar que la roca ha pasado por un proceso de constante deterioro, reflejando finas láminas muy quebradizas lo que nos sugirió una meteorización de largo tiempo en la roca, pues algunos grabados en la parte superior estaban incompletos quizás por este mismo fenómeno de desgaste. A pesar de contar con rocas dispersas alrededor del petroglifo no hemos podido hacer ensayos o experimentaciones de técnicas de percusión con replicas para demostrar la eficacia de estas herramientas, sin embargo, pensamos que al disponer del material arqueológico recolectado esperamos fabricar réplicas del mismo para experimentar su eficiencia y durabilidad.
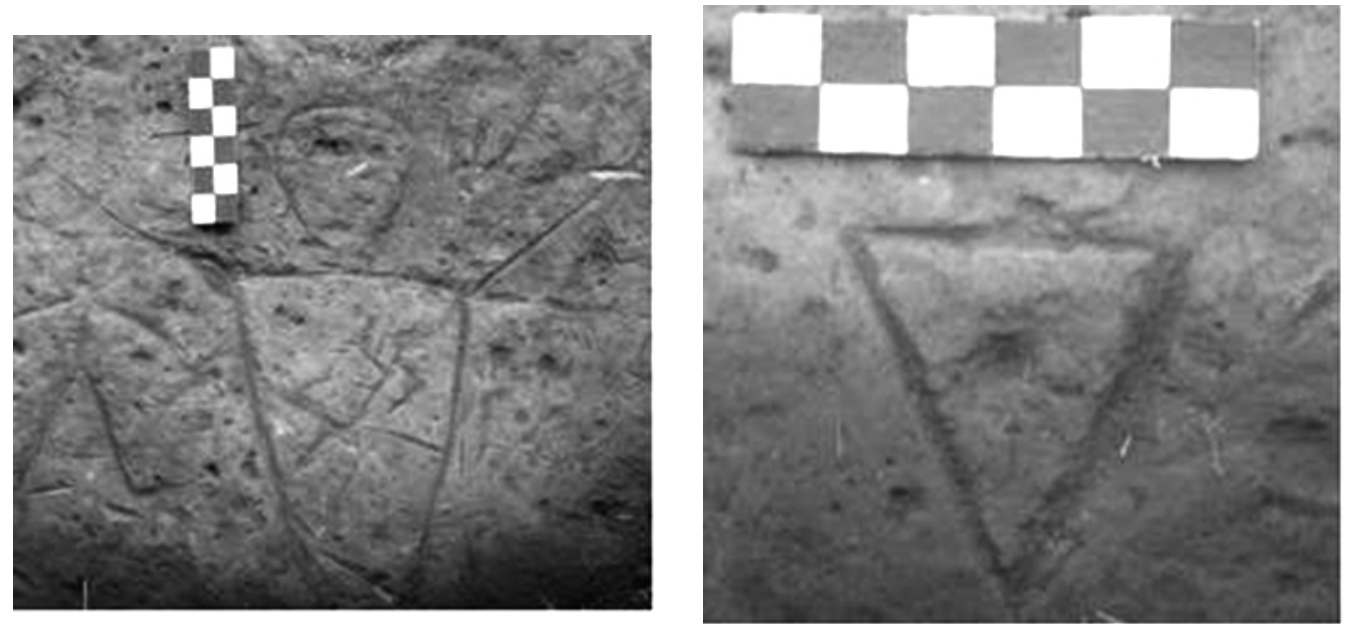

Figuras 3 y 4: grabados del petroglifo, a la izQuierda grabado de finas incisiones; derecha, GRABADO DE INCISIONES ANCHAS, QUE INDICA MAYOR FRICCIÓN Y DESGASTE DE LA HERRAMIENTA QUE LoS ANTERIORES. Todas Sugieren percusión indirecta. Fotos: Juan López Escorza, 2009.
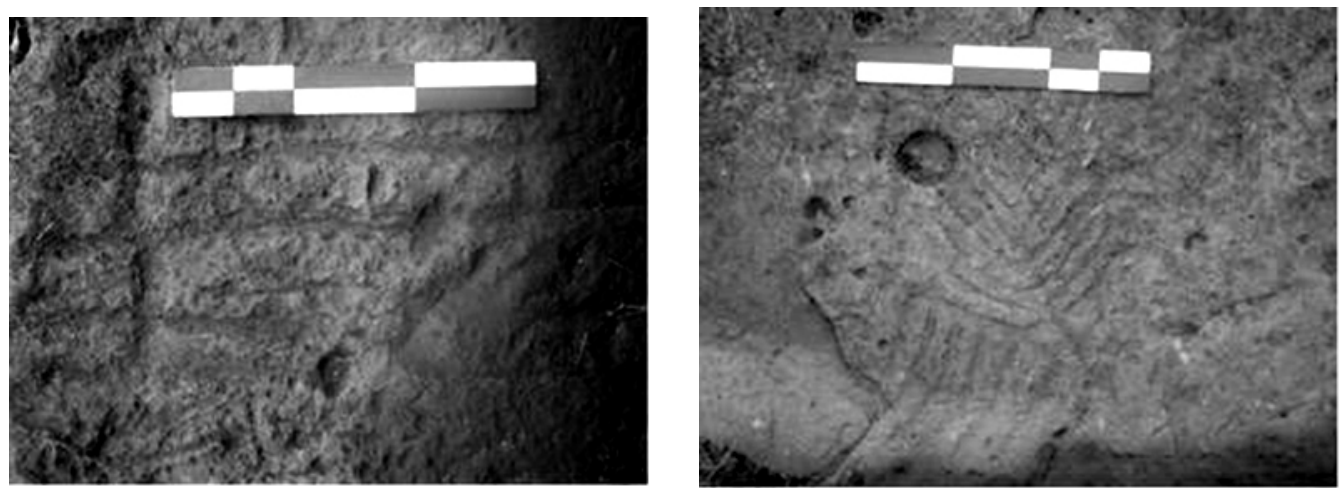

Figuras 5 y 6: Grabados de anchas acanaladuras en el petroglifo de La Libertad, indicadores de PERCUSIÓn INDIRECTA. Fotos: JuAn López EsCorza, 2009. 

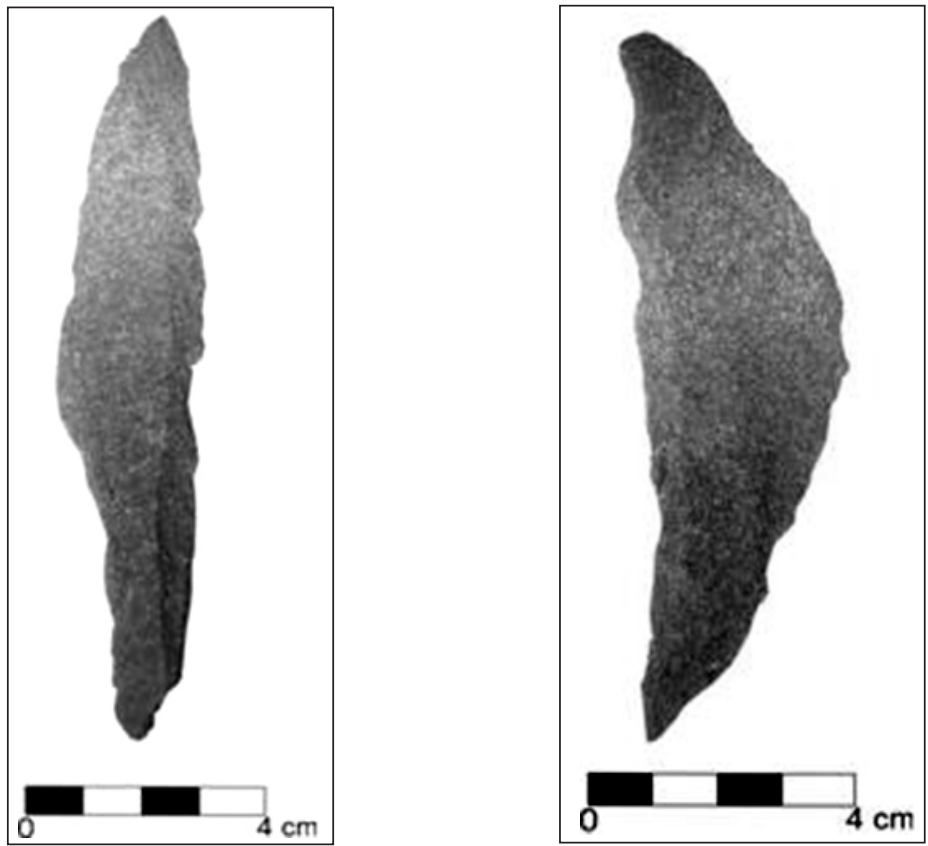

Figuras 7 y 8: Herramientas cinceles encontradas junto al petroglifo de La Libertad, a las Cuales hemos Clasificado COMO del tipo LL1 o bifaciales. Fotos: Juan López Escorza, 2009.
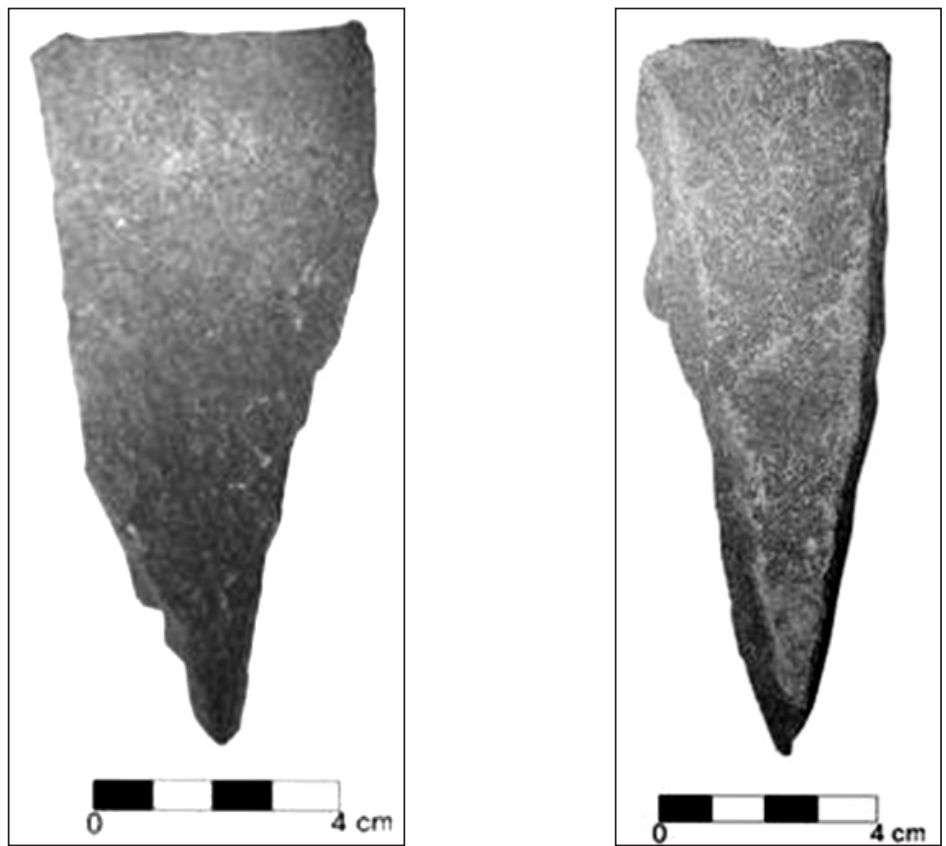

Figuras 9 y 10: Herramientas cinceles encontradas junto al petroglifo de La Libertad, a las CUALES HEMOS ClASIFICADO COMO LL2 O UNIFACIALES CON PLANO DE GOLPE. Fotos: JuAN LóPEZ EsCORZA, 2009. 
Los tipos de incisiones y acanaladuras son claramente diferenciables al comparar un grabado con otro, aunque se observa una predominancia de acanaladuras. Las incisiones aparecen tanto en grabados antropomorfos como geométricos, mientras que las acanaladuras o surcos predominan en los rasgos de figuras no definidas o incompletas dispersas en el petroglifo. Este aspecto es un indicador del uso de diferentes técnicas prehispánicas utilizadas al momento de hacer los grabados.

Como su nombre indica, las incisiones las podemos asociar a la técnica de incisiva para la cual en este sitio debieron utilizarse lascas de sílex u otro material de alto porcentaje de sílice, técnica que consiste en raspar con el filo de la lasca varias veces por el mismo trayecto (Fiore, 1999). Por otra parte, las acanaladuras o surcos están vinculadas al menos a tres técnicas que pueden ser: el cincelado, realizado con punta de cornamenta, el golpeteo con pedernal afilado; y/o el picoteo. Podemos observar en las acanaladuras los rasgos del golpeteo y el cincelado en otras. El empleo de estas técnicas también se sustenta en las herramientas que hemos citado anteriormente encontradas junto al petroglifo.

\section{Conclusiones}

En este breve trabajo se ha intentado aportar con dos criterios metodológicos que puedan brindar vinculaciones de tipo tecnológico entre un petroglifo y las posibles herramientas utilizadas para el diseño de grabados. El primero, relacionado con el tipo de herramientas cincel halladas junto al petroglifo, y el segundo criterio, definido por la variable desgaste asociada a su vez con los estilos de acanaladuras, surcos e incisiones de los grabados del petroglifo de La Libertad. Esta propuesta de comparación entre instrumentos-uso-grabados, no pretende brindar en ningún momento una explicación completamente satisfactoria para el arte rupestre de las estribaciones de la cordillera occidental ecuatoriana, sin embargo, pensamos que una mayor muestra de material permitiría no solamente hablar de las técnicas de percusión empleadas en periodos prehispánicos, sino poder encontrar suficiente material para reconstruir la cadena de producción de imágenes.

Es importante puntualizar que el estudio del arte rupestre no se limita únicamente al análisis estilístico, tipológico de grabados, sino también a encontrar posibles asociaciones de estos elementos con otras evidencias materiales dejadas en su entorno inmediato. A lo largo de este trabajo, se ha puesto énfasis en brindar una hipótesis sobre la técnica y la tecnología que utilizaron los grupos humanos de esta región para la manufactura de petroglifos en tiempos precolombinos.

Provisionalmente, los tipos de herramientas encontradas en asociación con los distintos rasgos de los grabados del sitio La Libertad, son una importante evidencia que nos plantea algunas interpretaciones sobre las técnicas de elaboración, en este caso se vislumbran al menos dos técnicas: por una parte, una posible percusión indirecta y por otra la percusión directa que igualmente han sido expuestas a lo largo del presente artículo basados en los argumentos de Fiore (1999) y otros arqueólogos que han experimentado en contextos similares. En el caso de esta última técnica hay dos posibles indicadores: el hallazgo de incisiones en algunos grabados, y el hallazgo de herramientas bifuncionales de perforación y/o fricción.

Nuestra interpretación provisional a lo largo de este artículo, es que no se ha reportado por ahora un contexto similar en nuestro país que se oponga a nuestro planteamiento de que varias técnicas pueden haber sido utilizadas en la cadena de producción de imágenes, igualmente, que distintos tipos de herramientas se aplicaron en la elaboración de un mismo petroglifo e inclusive en un mismo panel. Por ahora, nuestra conclusión preliminar se orienta a plantear que las técnicas de percusión directa e indirecta pueden ser utilizadas simultáneamente, que ninguna de estas técnicas es expresa de ciertos individuos, contextos sociales, o ambientes, sino que responde a una respuesta tecnológica inmediata a las condiciones en las que la cadena de producción de imágenes se desarrolla. 
Un aspecto fundamental que podemos plantear es que es posible, a partir de este breve estudio, comparar los grabados de La Libertad con los del sector de Bellavista y Sukibí ubicados dentro de la misma parroquia, donde hay rocas más duras y de mayor dimensión. En estos petroglifos, dada la alta frecuencia de acanaluduras o surcos, los grabados pudieron haber sido hechos en base a la técnica de percusión indirecta, es decir con golpeteo y picoteo. Esto quiere decir, que esta técnica pudo aportar en gran medida a proyección territorial del arte rupestre de esta zona, sugiriendo a la vez que que se trata de una técnica con mayor eficacia para trazar grabados en rocas más duras, no es así con la técnica de percusión directa a base de incisiones. Desde un punto de vista cognitivo, los individuos seleccionaban la técnica del grabado probablemente, según la dureza de la roca, esto quiere decir también que las técnicas de grabados estaban plenamente desarrolladas y consolidadas, aplicadas por talladores o grabadores especializados, formados a partir de una larga tradición, que pudo expandirse prominentemente en las estribaciones de la cordillera occidental ecuatoriana.

\section{Bibliografía}

Andrefsky, W. 2001, A brief introduction to lithic analysis, Cambridge University Press.

Bednarik, R.1993, Cupules, the Oldest Surviving rock art, International Federation of Rock Art Organisations (IFRAO), Australia.

Danae, F. 1999, Cuestiones teórico-metodológicas e implicaciones arqueológicas en la identificación de artefactos utilizados en la producción de grabados rupestres. Relaciones de la Sociedad Argentina de Antropología XXIV, Buenos Aires.

Estrada, E. 1979, Ensayo preliminar sobre la Arqueología de Milagro, Archivo Histórico del Guayas, Guayaquil.

Gilreath, A. 1997, Cultural Resources Inventory in Support of the Coso Rock Art District/ Landmark Boundary Study, Vols. I and II, Far Western Anthropological Research.

Holm, O. 1981, Cultura Milagro-Quevedo, editorial Talleres del Museo Antropológico del Banco Central del Ecuador. Guayaquil.

Idrovo Urigüen, J. 1994, Kuracazgos autónomos y el control de ecologías diversas, caso: la provincia de Bolivar, Universidad Estatal de Bolívar, Guaranda.

Lorandi, A. 1976, Propuesta de Método para un Análisis de estructura del Arte Rupestre, ActesDu XLII Congrés International ds Américanistes. Congrés du Centenaire, París, 2-9 September 1976. Volume IX-B., Fundation Singer Polignac, pp. 277-285.

López Escorza, J. 2009. Arqueología de los Petroglifos de San Luis de Pambil en la provincia Bolivar: interpretación desde el modelo neuropsicológico, Tesis de grado, Escuela de Antropología de la Pontificia Universidad Católica del Ecuador, Quito.

Porras, P. y Moncayo, P. 1983, Arqueología de Palenque en Los Ríos y la Poma en Guayas, Centro de Investigaciones Arqueológicas de la PUCE, Fondo Jijón y Caamaño, Banco Central del Ecuador, Quito.

Trubshaw, B. 2003, "What did prehistoric people think?: The science of cognitive archaeology", en: Mercian Mysteries, $\mathrm{n}^{\circ} .25$.

Wolf, Teodoro. 1975, Geografía y Geología del Ecuador (1892), publicado por orden del Supremo Gobierno de la República. CCE, Quito.

Winckfl, A. (s/f). Relieve y geomorfología del Ecuador, Misión ORSTOM en Ecuador, Quito.

Wilsem, E. 1968, “Archaeology Functional Analysis of Flaked Stone Artifacts", Author(s): Edwin N. Source: American Antiquity, Vol. 33, n. 2 (Apr., 1968), pp. 156161 Published. 